\title{
High-cholesterol diet enriched with onion affects endothelium-dependent relaxation and NADPH oxidase activity in mesenteric microvessels from Wistar rats
}

Diana González-Peña', Javier Angulo², Susana Vallejo ${ }^{3}$, Clara Colina-Coca', Begoña de Ancos', Carlos F Sánchez-Ferrer ${ }^{3}$, Concepción Peiró ${ }^{3}$ and Concepción Sánchez-Moreno ${ }^{1 *}$

\begin{abstract}
Background: The aim of the present study was to examine the effects of onion as functional ingredient on the oxidative status, lipoprotein levels (total cholesterol-TC, HDL-C, LDL-C), triacylglycerides (TAG) and vascular reactivity of mesenteric arteries in hypercholesterolemic Wistar rats.

Methods: Twenty-four animals were fed with three different diets [control, high-cholesterol diet $(\mathrm{HC})$ and high-cholesterol enriched with onion diet (HCO)]. After seven weeks of experimental feeding the rats were euthanized for blood and tissues collection. TC, HDL-C, LDL-C and TAG were measured, and 2,2'-azinobis-(3-ethylbenzothiazoline-6-sulfonic acid) radical cation $\left(\mathrm{ABTS}^{-+}\right.$) scavenging capacity and ferric reducing antioxidant power (FRAP) were determined in plasma. Superoxide dismutase (SOD) and glutathione peroxidase (GPx) enzyme activities were assayed in erythrocyte lysates. Endothelium-dependent vasodilation to acetylcholine was evaluated in mesenteric arterial segments. NADPH oxidase (NOX) was also measured by lucigenin-derived chemiluminiscence.

Results: The dietary cholesterol content significantly affected plasma lipoprotein levels, increased superoxide generation from NOX, and caused impaired endothelium-dependent vasodilation in the rat mesenteric arteries. Onion ingredient improved antioxidant status in HCO group, as it was evidenced by ABTS ${ }^{\cdot+}$ and FRAP values and SOD and GPX enzyme activities compared to the HC-fed group, reduced the increment in NOX activity and reversed endothelial dysfunction promoted by the HC diet. Scavenging of superoxide with TEMPOL or inhibition of NOX with apocynin improved endothelium-dependent vasodilation only in HC-fed rats.

Conclusions: Enrichment of diet with onion as functional ingredient could be proposed as a complementary approach to prevent or partially modulate vascular dysfunction, reducing some of the risk indexes linked to initial development of atherosclerosis.
\end{abstract}

Keywords: Onion, Functional foods, Dietary cholesterol, Mesenteric microvessels, NADPH oxidase

\footnotetext{
* Correspondence: csanchezm@ictan.csic.es

'Institute of Food Science, Technology and Nutrition (ICTAN),

Spanish National Research Council (CSIC), José Antonio Novais 10, ES-28040

Madrid, Spain

Full list of author information is available at the end of the article
}

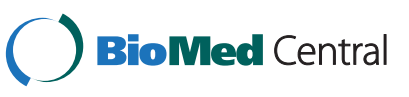

(c) 2014 González-Peña et al.; licensee BioMed Central. This is an Open Access article distributed under the terms of the Creative Commons Attribution License (http://creativecommons.org/licenses/by/4.0), which permits unrestricted use, distribution, and reproduction in any medium, provided the original work is properly credited. The Creative Commons Public Domain Dedication waiver (http://creativecommons.org/publicdomain/zero/1.0/) applies to the data made available in this article, unless otherwise stated. 


\section{Background}

The evolution of hypercholesterolemia is associated with a large range of alterations considered as strong risk factors for many negative cardiovascular events. Elevated oxidant stress linked to pro-inflammatory conditions contributes to the development of alterations in the bioavailability of vascular nitric oxide and some endothelial cell dysfunctions that can culminate in profound impairments to vascular reactivity [1]. The redox status linked to hypercholesterolemic conditions is affected by an imbalance between prooxidant and antioxidant enzymes, where NADPH oxidases (NOX), xanthine oxidase, and myeloperoxidase could be pointed as the major oxidant producing systems which lead to an overproduction of free radicals. In addition, some of the markers of oxidative stress might be used as a tool to predict cardiovascular risk, since its upregulation has been usually associated to inflammatory responses within the microvasculature $[2,3]$.

The vascular endothelium is a multifunctional organ system composed of metabolically active and physiologically responsive component cells that regulate blood flow depending on metabolic conditions. The sensitivity of such system is able to display evidences of endothelial dysfunction, like one of the earliest events in the development of atherosclerosis [4]. Dietary intake of certain nutrients has been suggested as an alternative in the prevention of several pathologies, as a gentle mean of modifying the mechanisms involved in the progression of cardiovascular disease [5-9]. Recent evidences in this line have pointed out the consumption of flavonoid-rich food such as wine and grape related products, chocolate and soya in the improvement of different endothelial functions [10-12], the consumption of the well-known rich in antioxidants Mediterranean diet in the amelioration of endothelial vasodilation in hypercholesterolemic subjects [13] and the decrease in the incidence of major cardiovascular events in persons with cardiovascular risk [14].

In this sense, the potential efficacy of onion consumption in the prevention of vascular damage have been highly supported by its hypolipidemic, antiinflamatory, antihypertensive, antidiabetic, antithrombotic, and antihyperhomocysteinemia effects $[15,16]$. Specific phytochemicals (flavonols, sulphur compounds) and nutritional compounds (dietary fibre) present on its matrix have been pointed out as main promoters of those cardioprotective effects [17-19]. However, the advantage of consuming the natural product instead of those separated compounds must be taken in consideration since interactions and synergistic effects shall be present and responsible for some specific health benefits. In this regard, a branch of the food processing field has focused its efforts in facilitating ready-to-use functional ingredients that preserve (or even improve) the quality, content of bioactive compounds, and the functional activities of the original raw material. The enhancement of some compounds present in onion, and their stabilization by using combined technologies have made available an stable functional food ingredient with great versatility and added value due to its potential biological activity [20].

The application of this so-called "functional ingredient" arises as a possible intervention for either the improvement of vascular function or as an alternative strategy in the prevention of the development of cardiovascular disease.

Consequently, the aim of the present study was to investigate the effects of onion as functional ingredient on lipid profile, oxidative status, and endothelium-dependent relaxation and NOX activity in mesenteric microvessels in hypercholesterolemic Wistar rats.

\section{Methods}

\section{Onion powder preparation}

Raw onions (Allium cepa L. var cepa, 'Recas') were supplied by Cebacat (Asociación Catalana de ProductoresComercializadores de Cebolla, Lleida, Spain). Onions were harvested in April 2012 in Spain and their bulbs were free of external damages and stored at $4^{\circ} \mathrm{C}$ until processing (5 days later). The onions were hand-peeled, cut into $10 \mathrm{~mm}$ pieces, packaged in bags with very low gas permeability (Doypack ${ }^{\oplus}$, Polyskin XL, Amcor Flexibles Hispania, S.L., Granollers, Barcelona, Spain) and treated by highpressure. Diced packed onions were exposed to $400 \mathrm{MPa}$ for a 5-min hold-time and processing unit temperature at $25^{\circ} \mathrm{C}$. After the high-pressure treatment, the onion was immediately frozen with liquid nitrogen, freeze-dried in a lyophilizer (model Lyoalfa, Telstar, S.A., Barcelona, Spain), pulverized with a ultra centrifugal mill ZM 200 (Retsch $\mathrm{GmbH}$, Haan, Germany) obtaining a fine powder (final size particle $\leq 250 \mu \mathrm{m}$ ), and stored at $-20 \pm 0.5^{\circ} \mathrm{C}$ until use. Nutritional composition, phytochemical compounds, and antioxidant activity of onion powder are shown in Table 1.

\section{Diet preparation and experimental design}

A total of twenty four male Wistar rats with a body weight of approximately $250 \mathrm{~g}$ at the outset were obtained from Harlan Laboratories Models (Harlan, SL, Barcelona, Spain). The animals were housed individually in metabolic cages in a temperature-controlled room $\left(22.5 \pm 0.5^{\circ} \mathrm{C}\right)$ with a $12 \mathrm{~h}$ light - $12 \mathrm{~h}$ dark cycle. The present study was approved by the Spanish Ministry of Science and Innovation Advisory Committee [project AGL2010-15910 (subprogram ALI)] and by an Ethics Committee of the Complutense University of Madrid (Spain). All experiments were performed in compliance with the Directive 2010/63/UE regarding the protection of animals used for scientific purposes. The rats were fed commercial rat pellets (Panlab, SLU, Barcelona, Spain) for 3 days for the adaptation to environmental conditions and then distributed into three groups of eight animals each, according 
Table 1 Nutritional composition, phytochemical compounds, and antioxidant activity of onion powder

\begin{tabular}{|c|c|}
\hline & Onion powder \\
\hline Protein $(\mathrm{g} / 100 \mathrm{~g})$ & $9.75 \pm 0.08$ \\
\hline Lipids (g/100 g) & $1.30 \pm 0.06$ \\
\hline Carbohydrates (g/100 g) & $80.10 \pm 2.89$ \\
\hline Glucose (g/100 g) & $27.7 \pm 1.73$ \\
\hline Fructose $(\mathrm{g} / 100 \mathrm{~g})$ & $20.7 \pm 0.46$ \\
\hline Sucrose (g/100 g) & $4.3 \pm 0.11$ \\
\hline Total fructans $(\mathrm{g} / 100 \mathrm{~g})$ & $4.2 \pm 0.10$ \\
\hline Total dietary fibre (g/100 g) & $23.2 \pm 1.15$ \\
\hline Soluble fibre (g/100 g) & $3.2 \pm 0.09$ \\
\hline Insoluble fibre (g/100 g) & $20.0 \pm 0.17$ \\
\hline Ash (g/100 g) & $4.63 \pm 0.07$ \\
\hline Total phenols (mg GAE/100 g) & $1629.6 \pm 60.0$ \\
\hline Quercetin 3-glucoside (mg/100 g) & $32.22 \pm 0.90$ \\
\hline Quercetin 4'-glucoside (mg/100 g) & $950.00 \pm 2.99$ \\
\hline Quercetin 3,4'-diglucoside (mg/100 g) & $1368.89 \pm 8.77$ \\
\hline Quercetin 7,4'-diglucoside (mg/100 g) & $31.56 \pm 0.33$ \\
\hline Quercetin 3,7,4'-triglucoside (mg/100 g) & $9.16 \pm 0.32$ \\
\hline Isorhamnetin 4'-glucoside (mg/100 g) & $45.16 \pm 1.54$ \\
\hline Isorhamnetin 3,4'-diglucoside (mg/100 g) & $32.00 \pm 0.19$ \\
\hline Total ACSOs (mg BCSOE/100 g) & $4120.89 \pm 89.43$ \\
\hline Propionaldehyde (mg/100 g) & $245.04 \pm 39.61$ \\
\hline 1-Propanethiol (mg/100 g) & $23.54 \pm 0.90$ \\
\hline Hexanal (mg/100 g) & $0.04 \pm 0.001$ \\
\hline 2-Methyl 2-pentenal (mg/100 g) & $10.80 \pm 0.67$ \\
\hline Propyl thioacetate (mg/100 g) & $0.45 \pm 0.03$ \\
\hline Dimethyl trisulfide (mg/100 g) & $66.41 \pm 5.02$ \\
\hline Dipropyl disulfide (mg/100 g) & $89.45 \pm 3.29$ \\
\hline Methyl propyl trisulfide (mg/100 g) & $42.28 \pm 2.14$ \\
\hline Dipropyl trisulfide (mg/100 g) & $25.50 \pm 2.45$ \\
\hline Ascorbic acid (mg/100 g) & $62.31 \pm 0.77$ \\
\hline Total vitamin C (mg/100 g) & $104.26 \pm 4.07$ \\
\hline Scavenging of $\mathrm{NO}^{*}(\mu \mathrm{mol} \mathrm{TE} / 100 \mathrm{~g})$ & $1706.00 \pm 49.61$ \\
\hline $\mathrm{ABTS}^{++}(\mu \mathrm{mol} \mathrm{TE} / 100 \mathrm{~g})$ & $4936.67 \pm 72.65$ \\
\hline $\mathrm{DPPH}^{\bullet}(\mu \mathrm{mol} \mathrm{TE} / 100 \mathrm{~g})$ & $1135.00 \pm 82.21$ \\
\hline FRAP $(\mu \mathrm{mol}$ TE/100 g) & $12245.14 \pm 60.45$ \\
\hline
\end{tabular}

Values are expressed as the mean $\pm S D(n=3)$.

GAE, gallic acid equivalents; ACSOs, S-alk(en)yl-L-cysteine sulfoxide; BCSOE, $S$-Butyl-L-cysteine sulfoxide equivalents; $\mathrm{NO}^{\text {; }}$, nitric oxide radical $\mathrm{ABTS}^{+}{ }^{+}$, 2,2'-azinobis(3-ethylbenzothiazoline-6-sulfonic acid) radical cation; $\mathrm{DPPH}^{\circ}$, 2,2-diphenyl-1-picrylhydrazyl radical; FRAP, ferric reducing antioxidant power; $\mathrm{TE}$, trolox equivalents.

to average body weight and fed the control diet for 4 days for the adaptation to the metabolic cages. The diets composition, based on the AIN-93 M semi-purified rodent diet [21], is shown in Table 2. The following three experimental semi-synthetic diets (Table 2) were prepared: (1) the control
Table 2 Composition of the experimental diets

\begin{tabular}{llll}
\hline Ingredient $\mathbf{( g / k g )}$ & Control & HC & HCO \\
\hline Onion powder & - & - & 100 \\
Casein & 200 & 200 & 200 \\
Sucrose & 100 & 100 & 100
\end{tabular}

Maize starch

$470.49 \quad 445.49$

368.69

Soya oil

$50 \quad 50$

Maize oil

80

Mineral mixture*

35

Vitamin mixture†

10

Cellulose powder

50

Choline bitartrate

tert-butylhydroquinone

$$
2.5
$$

0.010

\section{0}

50

L-cystine

2

Cholesterol

$-$

80

80

80

35

35

10

26.8

\section{Cholic acid}

$$
-
$$

10

50

2.5

$\mathrm{HC}$, high-cholesterol diet; $\mathrm{HCO}$, high-cholesterol enriched with onion diet. *Mineral mix for the AIN-93 M diet, $\mathrm{g} / \mathrm{kg}$ : calcium carbonate anhydrous, 357.00; potassium phosphate monobasic, 250.00; potassium citrate, tripotassium monohydrate, 28.00; sodium chloride, 74.00; potassium sulphate, 46.00; magnesium oxide, 24.00; ferric citrate, 6.06 ; zinc carbonate, 1.65 ; sodium meta-silicate $9 \mathrm{H}_{2} \mathrm{O}$, 1.45 ; manganous carbonate, 0.63 ; cupric carbonate, 0.30 ; chromium potassium sulfate $12 \mathrm{H}_{2} \mathrm{O}, 0.275$; boric acid, 0.0815 ; sodium fluoride, 0.0635 ; nickel carbonate, 0.0318 ; lithium chloride, 0.0174 ; sodium selenate anhydrous, 0.01025 ; potassium iodate, 0.0100 ; ammonium paramolybdate $4 \mathrm{H}_{2} \mathrm{O}, 0.00795$; ammonium vanadate, 0.0066; powdered sucrose, 209.806.

${ }^{\dagger}$ AIN-93-VX vitamin mix for the AIN-93 M diet, g/kg: niacin, 3.000; calcium pantothenate, 1.600; pyridoxine- $\mathrm{HCl}, 0.700$; thiamin- $\mathrm{HCl}, 0.600$; riboflavin, 0.600; folic acid, 0.200; biotin, 0.200; vitamin $\mathrm{B} 12$ (0.1\%), 2.500; vitamin E (all-rac-a-tocopheryl acetate, $500 \mathrm{lU} / \mathrm{g}$ ), 15.000; vitamin A (all-trans-retinyl palmitate, 500,000 IU/g), 0.800; vitamin D3 (400,000 IU/g), 0.250; vitamin K1, 0.075 ; powdered sucrose, 974.655 .

\#Diet energy content was calculated using the factors $16.73 \mathrm{~kJ} / \mathrm{g}$ (4 kcal/g) for protein, $15.69 \mathrm{~kJ} / \mathrm{g}(3.75 \mathrm{kcal} / \mathrm{g})$ for monosaccharides, $16.53 \mathrm{~kJ} / \mathrm{g}(3.95 \mathrm{kcal} / \mathrm{g})$

for disaccharides, $17.49 \mathrm{~kJ} / \mathrm{g}(4.18 \mathrm{kcal} / \mathrm{g})$ for starch, $8.37 \mathrm{~kJ} / \mathrm{g}(2 \mathrm{kcal} / \mathrm{g})$ for dietary fibre, and $37.65 \mathrm{~kJ} / \mathrm{g}$ for fat. Control diet, $18540.9 \mathrm{~kJ} / \mathrm{kg}$ (4431.4 kcal $/ \mathrm{kg}) ; \mathrm{HC}$ diet, $18856.6 \mathrm{~kJ} / \mathrm{kg}(4506.8 \mathrm{kcal} / \mathrm{kg}) ; \mathrm{HCO}$ diet, $18642.4 \mathrm{~kJ} / \mathrm{kg}(4455.6 \mathrm{kcal} / \mathrm{kg})$.

diet was composed of a homogeneous mixture of $100 \%$ rodent diet; (2) the high-cholesterol diet ( $\mathrm{HC}$ ) was the control diet with $2 \%$ cholesterol and $0.5 \%$ cholic acid, substituting an equal amount of maize starch; and (3) the highcholesterol diet enriched with onion (HCO) was identical to the high-cholesterol diet, but with $10 \%$ onion powder, balancing the dietary fibre with cellulose powder. The dose for onion powder was selected based on the body surface area normalization method and previous studies [22,23]. Water and food were provided ad libitum over the 7-week experimental period. Body weight and food consumption were recorded weekly and daily, respectively.

\section{Sampling}

At the end of the experiment, in order to avoid interassay variations that could affect the comparison of data from the different groups, animals in fasting conditions were anaesthetised and euthanized by extracting blood by cardiac puncture with a syringe, taking one animal at 
a time, of each one of three groups. Blood was collected from the heart and taken into tubes with EDTA as anticoagulant. Plasma was recovered after centrifugation $(1500 \mathrm{~g}, 15 \mathrm{~min})$ at $4^{\circ} \mathrm{C}$ and immediately stored at $-80^{\circ} \mathrm{C}$ until analysis. Third branch mesenteric arteries (lumen diameter 200-400 $\mu \mathrm{m}$ ) were obtained from rat omentum specimens and placed into ice-cold Krebs-Henseleit solution (KHS; composition in $\mathrm{mM}: \mathrm{NaCl} 119, \mathrm{KCl} 4.6, \mathrm{CaCl}_{2}$ 1.5, $\mathrm{MgCl}_{2}$ 1.2, $\mathrm{NaHCO}_{3}$ 24.9, glucose $11, \mathrm{KH}_{2} \mathrm{PO}_{4} 1.2$ and EDTA 0.027) and transported to the laboratory for dissection within $2 \mathrm{~h}$ of collection.

\section{Nutritional composition, phytochemical compounds, and antioxidant activity of onion powder}

Analysis of protein, lipids, total fructans, total dietary fibre and ash was performed using standard laboratory procedures [24]. Soluble sugars were determined by ion chromatography using the method described by ColinaCoca et al. [25].

Determination of total phenolic content according to the Folin - Ciocalteu method, identification and quantification of flavonols by HPLC-DAD and HPLC-ESI-MS, determination of total $S$-alk(en)yl-L-cysteine sulfoxide (ACSOs) by HPLC-DAD, determination of volatile compounds by headspace GC-MS, and measurement of ascorbic acid and total vitamin $\mathrm{C}$ by HPLC-DAD were performed using the methods described by González-Peña et al. [20], and Colina-Coca et al. [25,26].

Determination of nitric oxide radical $\left(\mathrm{NO}^{*}\right)$ scavenging capacity, 2,2'-azinobis(3-ethylbenzothiazoline-6-sulfonic acid) radical cation $\left(\mathrm{ABTS}^{*+}\right.$ ) scavenging capacity, 2,2diphenyl-1-picrylhydrazyl radical (DPPH') scavenging capacity, and ferric reducing antioxidant power (FRAP) were carried out using the methods described by GonzálezPeña et al. [20].

\section{Plasma cholesterol and triacylglycerides analyses}

The total cholesterol (TC), HDL-cholesterol (HDL-C), LDL-cholesterol (LDL-C) and triacylglycerides (TAG) were determined in the plasma using standard enzymatic colorimetric methods (SPINREACT, SA/SAU, Girona, Spain) using a COBAS INTEGRA 400 plus system (Roche Diagnostics Ltd., Rotkreuz, Switzerland). Atherogenic indexes (AI) were calculated as follows: AI (1) = LDL-C/HDL-C, AI (2) $=$ TC/HDL-C, AI (3) = (TC-HDL-C $/$ HDL-C.

\section{Plasma antioxidant activity analyses}

2,2'-azinobis(3-ethylbenzothiazoline- 6-sulfonic acid) radical cation $\left(\mathrm{ABTS}^{*+}\right)$ scavenging capacity and ferric reducing antioxidant power (FRAP) were carried out in plasma using the methods described by GonzálezPeña et al. [20] slightly modified.

\section{Erythrocyte antioxidant enzyme activities}

Blood was treated to obtain the erythrocyte lysates as specified in the kits before assaying for SOD and GPx activities. SOD and GPx, activities were measured using a Superoxide Dismutase Assay Kit (706002, Cayman Chemical), and a Glutathione Peroxidase Assay Kit (703102, Cayman Chemical), respectively.

\section{Endothelium-dependent relaxation analyses in mesenteric microvessels. Vascular reactivity}

Third branch mesenteric arteries were dissected by carefully removing the adhering fat tissue. Arterial ring segments (2 mm long) were subsequently mounted on microvascular wire myographs (J.P. Trading, Aarhus, Denmark) for isometric tension recordings as previously described [27,28]. The vessels were allowed to equilibrate for $30 \mathrm{~min}$ in KHS continuously bubbled with $95 \% \mathrm{O}_{2} / 5 \% \mathrm{CO}_{2}$ mixture to maintain a $\mathrm{pH}$ of 7.4. Passive tension and internal circumference of vascular segments when relaxed in situ under a transmural pressure of $100 \mathrm{mmHg}\left(\mathrm{L}_{100}\right)$ were determined. The arteries were then set to an internal circumference equivalent to $90 \%$ of $\mathrm{L}_{100}$, at which the force development was close to maximal [29]. The preparations were then exposed to $125 \mathrm{mM} \mathrm{K} \mathrm{K}^{+}$(KKHS, equimolar substitution of $\mathrm{NaCl}$ for $\mathrm{KCl}$ in $\mathrm{KHS}$ ) and the contractile response was measured. After a stabilization period, rat arteries were contracted with 1-3 $\mu \mathrm{M}$ noradrenaline (NA, $80 \%$ of KKHS induced contraction, approximately) and relaxation responses were evaluated by cumulative additions of acetylcholine $(\mathrm{ACh} ; 1 \mathrm{nM}$ to $30 \mu \mathrm{M})$, to the chambers. Experiments were run in parallel. For determining the effects of superoxide scavenging and inhibition of NOX on endothelium dependent responses, arterial segments were incubated for $30 \mathrm{~min}$ with TEMPOL $(10 \mu \mathrm{M})$ or apocynin $(10 \mu \mathrm{M})$, respectively. Concentration-response curves to $\mathrm{ACh}$ in arterial segments from the same animal that previously received only vehicle (distilled water) were considered as controls for the evaluation of the effects of these treatments. For the evaluation of the impact of hypercholesterolemia on endothelium-independent vasodilatations, cumulative additions of sodium nitroprusside (SNP; $1 \mathrm{nM}$ to $100 \mu \mathrm{M})$ were added on NA-precontracted arterial segments from control and $\mathrm{HC}$-fed rats.

\section{NADPH oxidase activity in mesenteric microvessels}

The activity of NADPH oxidase (NOX) was measured by lucigenin-derived chemiluminiscence [28]. Mesenteric arteries from control, $\mathrm{HC}$-, and $\mathrm{HCO}$-fed rats were snap frozen in liquid $\mathrm{N}_{2}$ and stored at $-80^{\circ} \mathrm{C}$ until $\mathrm{NOX}$ activity assay. Arterial tissue was homogenized in lysis buffer (pH 7.0) containing $50 \mathrm{mmol} / \mathrm{L} \mathrm{KH}_{2} \mathrm{PO}_{4}, 1 \mathrm{mmol} / \mathrm{L}$ EGTA and $150 \mathrm{mmol} / \mathrm{L}$ sucrose for $5 \mathrm{~min}$ at $4^{\circ} \mathrm{C}$. For every sample, the protein content was determined by the bicinchoninic acid method. Vascular extracts were incubated in 
phosphate-buffered saline containing $5 \mu \mathrm{mol} / \mathrm{L}$ lucigenin and $100 \mu \mathrm{mol} / \mathrm{L} \mathrm{NADPH}$ and luminiscence was then measured every $30 \mathrm{~s}$ for $5 \mathrm{~min}$ in a microplate luminometer (Berthold Orion II, Titertek-Berthold, Pforzheim, Germany). The enzymatic activity was expressed as relative light units (RLU)/mg of protein/min.

\section{Statistical analyses}

Results are expressed as mean values with their SD or SEM as appropriate. Data were analysed using one-way ANOVA. Levene's test was applied to verify the homogeneity of the variances. Tamhane's T2 (equal variances not assumed) and Bonferroni (equal variances assumed) post hoc tests were used to determine differences within groups with significance set at $P<0.05$. Analyses were performed using the IBM SPSS Statistics 21 (SPSS Inc., an IBM Company). Relaxation responses are expressed as the percentage of the remaining noradrenaline-induced contraction. $\mathrm{pD}_{2}$ is defined as the $-\log \mathrm{M}$ of the concentration required to obtain $50 \%$ of maximal relaxation. Complete concentration-response curves were obtained and compared by two-way ANOVA using StatView software for Apple computers (SAS, Cary, NC).

\section{Results}

\section{Food intake and body weight gain}

The food intake (g/day) of the rats did not differ among the groups during the feeding period $(16.14 \pm 0.20$ for control, $15.99 \pm 0.18$ for $\mathrm{HC}$, and $16.33 \pm 0.26$ for $\mathrm{HCO})$. As the growth curve shows (Figure 1), there was no significant difference in the body weight gain $(\mathrm{g})$ among the three groups after the feeding period (141.80 \pm 9.75 for control, $133.68 \pm$ 6.93 for $\mathrm{HC}$, and $132.00 \pm 9.36$ for $\mathrm{HCO})$.

\section{Plasma and erythrocyte antioxidant activity}

The effect of an onion-enriched diet on plasma antioxidant activity $\left(\mathrm{ABTS}^{\circ+}\right.$ and FRAP values) and erythrocyte antioxidant enzyme (SOD and GPx) activities in

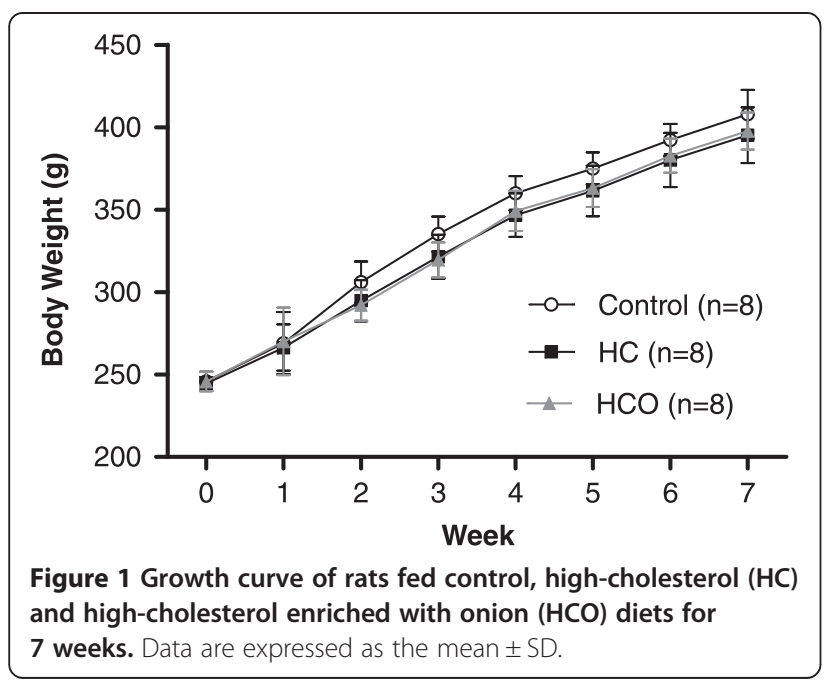

hypercholesterolemic Wistar rats is summarised in Table 3. The HCO-fed group had higher $\mathrm{ABTS}^{\bullet+}$ values compared to the control group and the HC-fed group. In concordance, the $\mathrm{HCO}$-fed group had higher FRAP values compared to the $\mathrm{HC}$-fed group. However, plasma $\mathrm{ABTS}^{\circ+}$ and FRAP values were not different between the control and the $\mathrm{HC}$-fed groups. In contrast, SOD and GPx enzyme activities decreased significantly in $\mathrm{HC}$-fed group compared to the control group. Nevertheless, those rats additionally fed with the functional ingredient maintained SOD activity in the same level as the control group, whereas GPx increased its activity compared to HC-fed group.

\section{Plasma cholesterol and triacylglycerides levels}

Dietary cholesterol content significantly affected plasma lipoprotein levels (Table 4). Rats fed the HC diet showed significantly higher plasma TC and LDL-C levels compared to the rats fed the control diet. Rats fed the $\mathrm{HCO}$ diet also showed significantly higher plasma TC and LDL-C levels compared to the rats fed the control diet. TC and LDL-C levels were not different between the $\mathrm{HC}$ - and HCO-fed groups. HDL-C levels were not different among the groups. The HC- and HCO-fed groups had higher atherogenic indexes compared to the control group. The HC- and HCO-fed groups had significantly lower TAG compared to the control group. TAG levels were not different between the $\mathrm{HC}$ - and $\mathrm{HCO}$-fed groups.

\section{Onion ingredient reverses endothelial dysfunction induced by high-cholesterol diet}

Acetylcholine (ACh; $1 \mathrm{nM}$ to $30 \mu \mathrm{M}$ ) caused endotheliumdependent vasodilation in rat mesenteric arteries which was significantly impaired in rats fed with a $\mathrm{HC}$ diet (Figure 2). In contrast, endothelium-independent vasodilation induced by the NO donor, sodium nitroprusside (SNP; 1 to $100 \mu \mathrm{M}$ )

Table 3 Plasma ABTS $^{*+}$ and FRAP values and erythrocyte antioxidant enzyme activities in rats fed the control, high-cholesterol (HC) and high-cholesterol enriched with onion (HCO) diets for 7 weeks

\begin{tabular}{lcrl}
\hline & Control & HC & HCO \\
\hline Plasma & & & \\
ABTS $^{+}(\mu \mathrm{mol}$ TE/L) & $6700.90 \pm 72.76^{\mathrm{a}}$ & $6634.29 \pm 66.50^{\mathrm{a}}$ & $6976.52 \pm 39.96^{\mathrm{b}}$ \\
FRAP $(\mu \mathrm{mol} \mathrm{TE} / \mathrm{L})$ & $229.42 \pm 15.71^{\mathrm{ab}}$ & $201.22 \pm 10.43^{\mathrm{a}}$ & $258.96 \pm 18.40^{\mathrm{b}}$ \\
Erythrocyte & & & \\
SOD $(\mathrm{U} / \mathrm{mL})$ & $266.52 \pm 27.66^{\mathrm{b}}$ & $169.03 \pm 15.16^{\mathrm{a}}$ & $263.24 \pm 22.78^{\mathrm{b}}$ \\
GPx $(\mathrm{nmol} / \mathrm{mL} / \mathrm{min})$ & $20.27 \pm 2.46^{\mathrm{c}}$ & $4.55 \pm 0.70^{\mathrm{a}}$ & $12.98 \pm 0.87^{\mathrm{b}}$ \\
\hline
\end{tabular}

Values are expressed as the mean \pm SEM ( $n=8$ rats per group). $\mathrm{HC}$, high-cholesterol diet; $\mathrm{HCO}$, high-cholesterol enriched with onion diet Mean values within a row with unlike superscript letters were significantly different $(P<0.05)$. One-way ANOVA and posterior Tamhane's T2 and Bonferroni post hoc tests were used as appropriate. 
Table 4 Plasma total cholesterol, HDL-cholesterol, LDL-cholesterol, triacylglycerides and atherogenic indexes in rats fed the control, high-cholesterol (HC) and high-cholesterol enriched with onion (HCO) diets for 7 weeks

\begin{tabular}{llcc}
\hline & Control & HC & HCO \\
\hline Total cholesterol $(\mathrm{mg} / \mathrm{dL})$ & $83.88 \pm 6.86^{\mathrm{a}}$ & $198.25 \pm 10.61^{\mathrm{b}}$ & $224.88 \pm 16.02^{\mathrm{b}}$ \\
HDL-cholesterol $(\mathrm{mg} / \mathrm{dL})$ & $60.00 \pm 4.94^{\mathrm{a}}$ & $51.50 \pm 3.74^{\mathrm{a}}$ & $61.75 \pm 4.12^{\mathrm{a}}$ \\
LDL-cholesterol $(\mathrm{mg} / \mathrm{dL})$ & $11.88 \pm 0.69^{a}$ & $118.63 \pm 8.23^{b}$ & $123.50 \pm 9.18^{b}$ \\
Al (1) & $0.205 \pm 0.019^{a}$ & $2.398 \pm 0.255^{b}$ & $2.083 \pm 0.223^{b}$ \\
Al (2) & $1.405 \pm 0.036^{a}$ & $3.959 \pm 0.307^{b}$ & $3.711 \pm 0.292^{b}$ \\
Al (3) & $0.405 \pm 0.036^{a}$ & $2.959 \pm 0.307^{b}$ & $2.711 \pm 0.292^{b}$ \\
Triacylglycerides (mg/dL) & $84.38 \pm 6.69^{\mathrm{b}}$ & $40.50 \pm 3.06^{\mathrm{a}}$ & $32.63 \pm 2.60^{\mathrm{a}}$ \\
\hline
\end{tabular}

Values are expressed as the mean \pm SEM ( $n=8$ rats per group).

$\mathrm{HC}$, high-cholesterol diet; $\mathrm{HCO}$, high-cholesterol enriched with onion diet.

Mean values within a row with unlike superscript letters were significantly different $(P<0.05)$. One-way ANOVA and posterior Tamhane's T2 and Bonferroni post

hoc tests were used as appropriate, italic small letters indicate Tamhane's T2 post hoc test.

$\mathrm{Al}$, atherogenic index (1): LDL-cholesterol/HDL-cholesterol; Al (2): Total cholesterol/HDL-cholesterol; Al (3): (Total cholesterol-HDL-cholesterol)/HDL-cholesterol.

was not altered in HC-fed group and was not further enhanced by onion supplementation ( $E_{\max }: 90.5 \pm 2.1 \%$, $88.6 \pm 5.4 \%$ and $78.1 \pm 6.7 \%$ for control, HC-, and HCO-fed groups, respectively; n.s.). Then, it was evaluated the effects of onion enrichment on the alteration caused by $\mathrm{HC}$ diet on endothelial function. HCO diet completely prevented the impairment of endothelium-dependent vasodilation in mesenteric arteries from rats fed with a $\mathrm{HC}$ diet (Figure 2). There were no significant differences among the groups regarding the contraction induced by $120 \mathrm{mM} \mathrm{K}+(12.6 \pm 0.5$

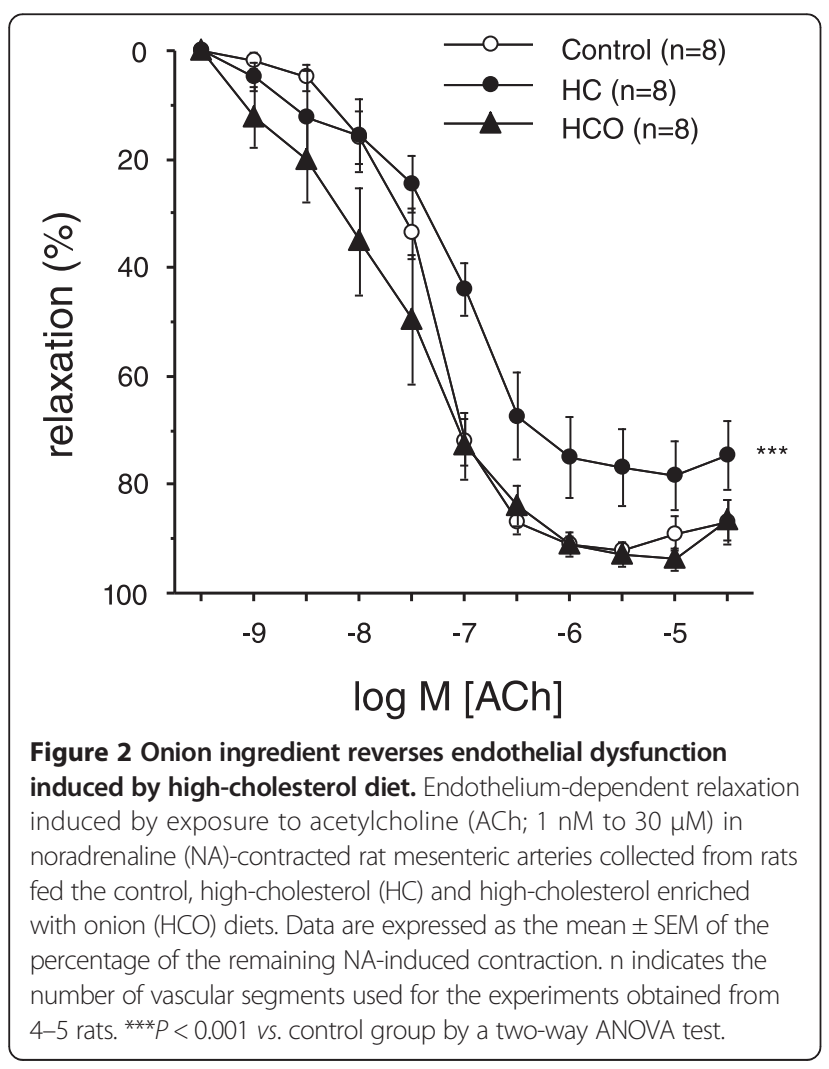

$\mathrm{mN}, 13.5 \pm 1.1 \mathrm{mN}$ and $13.6 \pm 1.0 \mathrm{mN}$ for control, $\mathrm{HC}-$, and HCO-fed groups, respectively) and the contractile tone induced by noradrenaline to evaluate relaxation experiments $(9.8 \pm 0.8 \mathrm{mN}, 11.8 \pm 2.0 \mathrm{mN}$ and $11.5 \pm 0.8 \mathrm{mN}$ for control, $\mathrm{HC}-$, and HCO-fed groups, respectively).

Increased superoxide generation from NADPH oxidase is responsible for high-cholesterol-induced endothelial dysfunction and is prevented by onion ingredient

While scavenging of superoxide anions with the permeable superoxide dismutase mimetic, TEMPOL $(10 \mu \mathrm{M})$, did not modify ACh-induced responses in mesenteric arteries from control group, the same treatment resulted in a significant improvement of endothelium-dependent vasodilation in mesenteric arteries from $\mathrm{HC}$-fed group (Figure $3 \mathrm{~A}$ and $3 \mathrm{~B}$ ). The improving effect induced by TEMPOL was absent in mesenteric arteries from HCOfed group, in which evidence for endothelial dysfunction was not observed (Figure 3C). In fact, after TEMPOL treatment no differences in ACh-induced vasodilation were observed among the three groups $\left(\mathrm{pD}_{2}\right.$ of $7.39 \pm$ $0.10,7.65 \pm 0.22$ and $7.59 \pm 0.32$ for control, HC-, and HCO-fed groups, respectively).

Since these results points to an increased generation of superoxide anions responsible for the endothelial dysfunction in HC-fed group, the role of NOX was investigated. Inhibition of NOX with apocynin $(10 \mu \mathrm{M})$ did not modify ACh-induced vasodilation in control group, while a significant improvement of endothelial vasodilation in HC-fed group was observed, which was comparable in magnitude to that exerted by TEMPOL (Figure 3A and 3B). No effects induced by apocynin were observed in mesenteric arteries from HCO-fed group (Figure 3C). Analogously to that observed with TEMPOL, the differences in ACh-induced responses among the three groups of rats disappeared in the presence of the NOX inhibitor $\left(\mathrm{pD}_{2}\right.$ of $7.46 \pm 0.22,7.58 \pm$ 0.31 and $7.41 \pm 0.20$ for control, HC-, and HCO-fed groups, 

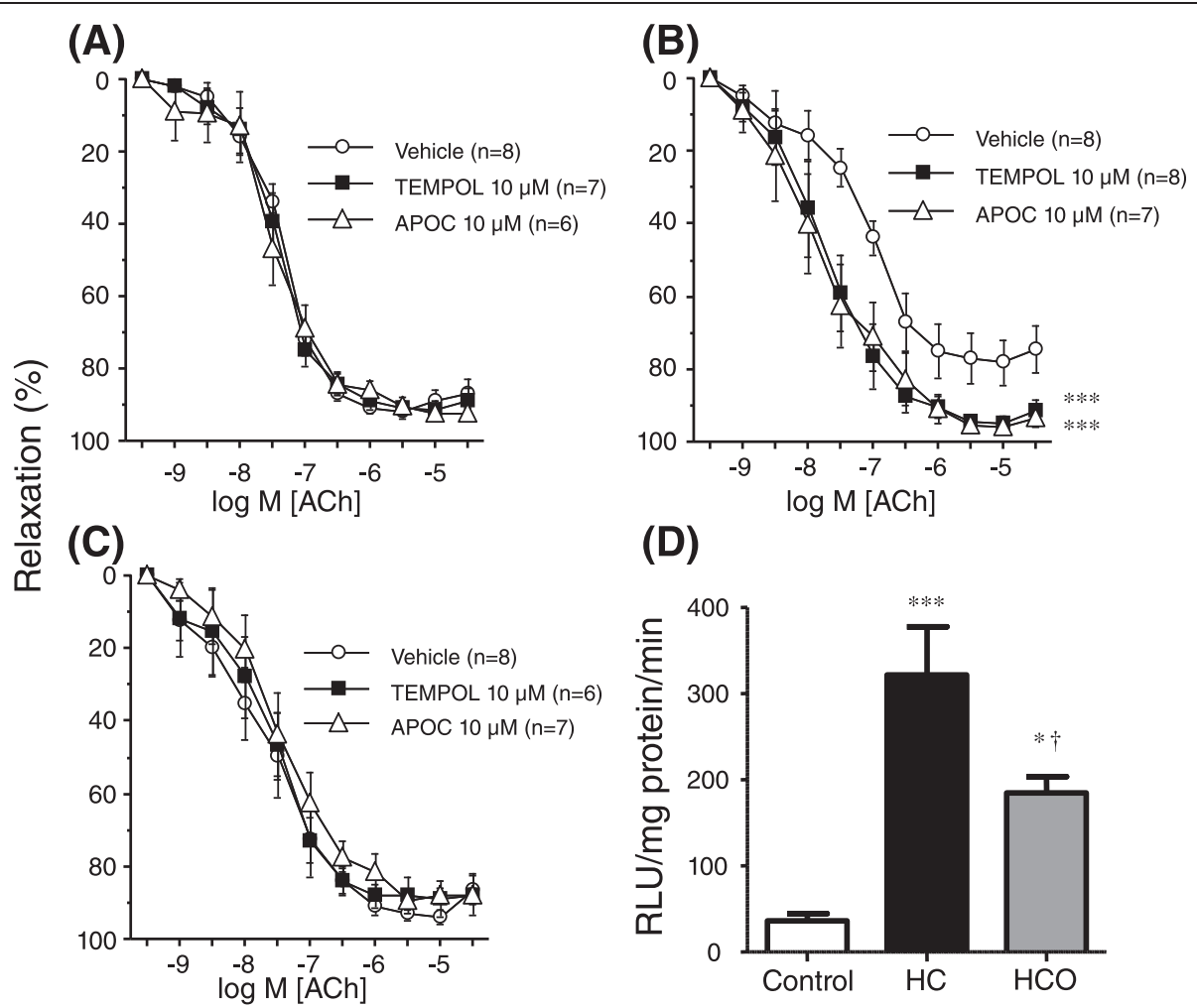

(D)

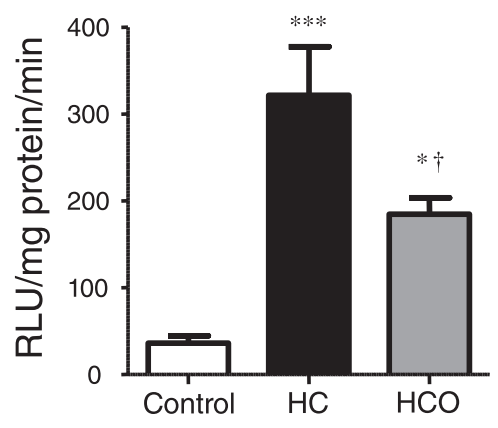

Figure 3 Increased superoxide generation from NADPH oxidase is responsible for high-cholesterol-induced endothelial dysfunction and is prevented by onion ingredient. Effects of the superoxide dismutase analogue, TEMPOL $(10 \mu \mathrm{M})$, and the NADPH oxidase inhibitor, apocynin (APOC; $10 \mu \mathrm{M}$ ) on endothelium-dependent relaxation induced by exposure to acetylcholine (ACh; $1 \mathrm{nM}$ to $30 \mu \mathrm{M}$ ) in noradrenaline (NA)-contracted rat mesenteric arteries collected from rats fed the control diet (A), rats fed the high-cholesterol diet (HC) (B) and rats fed the high-cholesterol enriched with onion diet (HCO) (C). Data are expressed as the mean \pm SEM of the percentage of the remaining NA-induced contraction. $\mathrm{n}$ indicates the number of vascular segments used for the experiments obtained from $4-5$ rats. ${ }^{* * *} P<0.001 \mathrm{vs}$. control by a two-factors ANOVA test. Panel D shows determination of superoxide anions generated from NADPH oxidase by lucigenin-derived chemiluminiscence in mesenteric arteries collected from rats fed the control, $\mathrm{HC}$ and $\mathrm{HCO}$ diets. Data are expressed as mean \pm SEM of relative light units (RLU)/mg of protein/min corresponding to 3 to 5 experiments. ${ }^{*} P<0.05$, ${ }^{* *} P<0.001$ vs. control group, $+P<0.05$ vs. HC group by a one-way ANOVA followed by Student-Newman-Keuls test.

respectively; n.s.). Neither TEMPOL nor apocynin affected contractile tone induced by noradrenaline in mesenteric arteries from control $(84.6 \pm 6.4 \%, 84.9 \pm 8.2 \%$ and $96.7 \pm$ $5.5 \%$ of $\mathrm{K}^{+}$-induced contraction for vehicle, TEMPOL and apocynin, respectively; n.s.), HC-fed (87.6 $\pm 8.1 \%, 73.0 \pm$ $7.1 \%, 79.1 \pm 6.6 \%$ of $\mathrm{K}^{+}$-induced contraction for vehicle, TEMPOL and apocynin, respectively; n.s.), or HCO-fed groups $\left(81.4 \pm 6.5 \%, 84.7 \pm 8.0 \%, 77.3 \pm 6.6 \%\right.$ of $\mathrm{K}^{+}$-induced contraction for vehicle, TEMPOL and apocynin, respectively; n.s.).

\section{Onion ingredient reduces the increment in NADPH oxidase activity induced by high-cholesterol diet in rat mesenteric arteries}

To confirm the contribution of NOX to the increase in superoxide anion generation in mesenteric arteries from $\mathrm{HC}$-fed rats suggested by the pharmacological inhibition of NOX in vascular reactivity studies, NOX activity in rat mesenteric arteries from the different groups was assessed. A significant increase in the NOX activity was observed in arteries obtained from $\mathrm{HC}$-fed group, which was significantly reduced, but not abolished, in vessels from HCO-fed group (Figure 3D).

\section{Discussion}

The present results evidence a clear positive effect of an onion-enriched diet on the preservation of the endotheliumdependent relaxation functions in the mesenteric arteries versus the impairment caused by a daily high-cholesterol intake (Figure 2). The development of the endothelial dysfunction is widely known to be influenced by several factors, such as the presence of insulin resistance, systemic inflammation, hypertension, or dysfunctional adipose tissue [30]. Obesity has been also associated with chronic inflammatory processes, atherosclerosis and oxidative stress, so constituting a pattern of microvascular dysfunction [31,32]. Along with all these multiple disorders, the disruption of the metabolism of lipoproteins occurs involving an increased level 
of circulating LDL-C that, together with changes in the endothelial permeability, promote its entry and retention in the wall of the artery [33]. Consequently, it points out the hypercholesterolemia as an independent factor of risk for the progression of vascular dysfunction, atherosclerosis and cardiovascular disease $[1,34]$.

In this study the supplementation with cholesterol and cholic acid acting as a potential atherogenic diet was clearly reflected by the increased plasma TC and LDL-C levels. Nevertheless, no significant changes in HDL-C in $\mathrm{HC}$ - and $\mathrm{HCO}$-fed groups, but a slight trend to decrease in $\mathrm{HC}$-fed group compared to the control group, were appreciated. Atherogenic ratios [AI (1), AI (2) and AI (3) Table 4] were unaffected between both $\mathrm{HC}$ - and HCOfed groups, suggesting that the removal of cholesterol from the circulation was not enhanced by onion intake. However, several studies highlight a rise in TAG in HCfed groups $v s$. control groups, while some of them show decreased levels of TAG in plasma or serum [35-38]. In this regard, the results in the present study showed decreased TAG levels after HC feeding (Table 4), thus differing from those studies where the hypercholesterolemia event (showing increased plasma TC and LDL-C, and decreased HDL-C levels) is simultaneously accompanied by an elevation of TAG and its reversion toward a basal status is achieved after feeding by specific diets (containing extracts or functional ingredients) or pharmacological interventions [39-43]. The concentration of TAG in the plasma at any time is generally the result of the balance between (I) the rate of entry of TAG into the plasma and (II) its rate of removal. In this sense, a possible cause of the cholesterol-induced hypotriglyceridemia may be the displacement of TAG by CE (cholesteryl esters) in newly formed VLDL particles. This mechanism has been recently described in Lxra-/- mice, accompanied by a decrease in lipogenic gene expression and a markedly reduced VLDL-TG production in cholesterol-fed animals [44]. Additionally, steatosis and hypotriglyceridemia in mice was reported by Werner et al. [45], concluding that this effect is a combined result of unimpaired hepatic TAG secretion, an increased hepatic synthesis of nonEFAs and the secretion of large VLDL particles, which may be subject to rapid clearance rates during EFA deficiency and development. Nonetheless, several mechanisms could be involved in this process since both cholesterol and bile acid metabolisms are involved in this tight regulation, as well as onion-enriched diet might be contributing to set the low TAG levels in the HCO-fed group, as a slight trend is appreciated when comparing HCO- and HC-fed groups [46,47].

In addition to hypercholesterolemia, oxidative stress is known a major factor leading to endothelial dysfunction, with significant prognostic implications for cardiovascular events. Thus, enhanced reactive oxygen species (ROS) production by different isoforms of the NADPH oxidase present in the vascular wall are involved in vascular pathologies, such as hypertension, inflammation, atherosclerosis, and diabetic vasculopathy [48]. The contribution of onion antioxidants and related bioactive substances was expected to have some influence in the control of ROS production, depletion of antioxidant status, and NOX activity triggered by high dietary cholesterol. According to our previous hypothesis, the findings in this study on plasma antioxidant activity evidenced significantly higher $\mathrm{ABTS}^{*+}$ and FRAP plasma values in rats fed the HCO diet compared to those fed the control diet. This fact was in line with the preventive effect achieved in superoxide anions generation promoted by NOX, which confirmed that onion supplementation can reduce the exacerbated NOX activity mediating endothelial dysfunction in the mesenteric arteries from the hypercholesterolemic animals (Figure 2). In addition, the consumption of onion as functional ingredient prevented the depletion of SOD and GPx enzyme activities, suggesting also a higher capacity of $\mathrm{HCO}$ fed-group by detoxifying ROS, in agreement with recent studies $[49,50]$.

The vascular-protective role of flavonoids (and especially their antioxidant properties) is an active field under investigation to improve the endothelial function through the modification of the oxidative stress status [51]. The onion powder used in the current study presented quercetin and isorhamnetin derivatives as major flavonols on its composition (Table 1), highlighting that a preventive function on AngII-induced endothelial dysfunction and an increased response to NO can be achievable with both compounds too [52]. Moreover, Shen et al. [53] have recently shown how the supplementation of quercetin is able to induct heme oxygenase-1 ( $\mathrm{HO}-1)$ protein expression, protecting endothelial cells against oxidative damage. Among other factors such as a reduced ERK1/2 phosphorylation, a decreased $\mathrm{NF}_{\mathrm{K}} \mathrm{B}$ activation and a downregulation of the Ob-Ra expression [54] or the inhibition of pro-inflammatory cytokines $[55,56]$ that have proved the anti-inflammatory effects exerted by quercetin.

Furthermore, interesting results have been described for raw onion and onion extracts in relation to the inhibition of platelet aggregation [57], anti-apoptotic activity in DOX-mediated entothelial cells [58], antioxidant protection against lipoprotein oxidation and oxidative stress $[47,59]$, and regulation of endogenous $\mathrm{H}_{2} \mathrm{~S}$ pathway $[60,61]$.

The mechanisms of action by which onion can enhance vasodilatory responses are multiple. McNeill and Jurgens [62] reported the implication of the endotheliumdependent vasodilatation, nitric oxide and cGMP mediated vasodilation in response to Welsh onion extract in the aorta of rats. The improving effects of $\mathrm{HCO}$ diet on endothelial vasodilation are not related to a potentiation 
of NO/cGMP pathway-mediated relaxation of smooth muscle since $\mathrm{HCO}$ diet did not enhance relaxant capacity of SNP beyond a preserved response in mesenteric arteries from $\mathrm{HC}$-fed rats. In the present work, the hypercholesterolemia induced by cholesterol supplementation has been clearly associated with the imbalance status achieved in mesenteric arteries in Wistar rats, by forcing endothelial dysfunction, affecting endothelium-dependent vascular smooth muscle relaxing capability, as well as involving NOX stimulation. On the other hand, the intake of the onion as functional ingredient during seven weeks evidenced an improvement and total reversion of such negative effects, specifically in response to cumulative dose of ACh. It has been suggested that apocynin could act as an antioxidant rather than a NOX inhibitor in vascular cells because of the lack of myeloperoxidase (MPO) activity that converts apocynin into its radical form that generates active dimers [63]. However, in addition to the fact that non-MPO peroxidases could account for the formation of apocynin dimers and trimers in vascular tissue [64], in the present study culture cells are not being evaluated, but a complete arterial segment that could easily contain MPO activity, mainly in hypercholesterolemic animals since hypercholesterolemia facilitates MPO activity increase in vascular tissues $[65,66]$. Thus, although the antioxidant capacity of apocynin could account for its reversing effects on hypercholesterolemia-associated endothelial dysfunction, it would be reasonable to consider that such effects are contributed by the ability of apocynin to inhibit NOX. The involvement of increased NOX activity in the impairment of endothelial vasodilation caused by hypercholesterolemia is supported by the fact that elevated NOX activity is detected in mesenteric arteries from HC-fed rats. This suggests that onion metabolites (or the changes that they may induce in metabolism) may partially reduce the increased NOX activity in the hypercholesterolemic rats, which can help to reduce the risk of some pathologies like CVD to a certain extent. Although a direct inhibitory effect on vascular NOX activity by onion metabolites cannot be discarded, the enhancement of the plasma antioxidant activity likely reflects a systemic reduction of the prooxidant and pro-inflammatory status in these animals. However, other studies regarding the contribution of eicosanoids products, the role of $\mathrm{K}+$ and calcium channel, or EDHF, among others [67], should be further explored to know all mechanisms of action contributing to vasodilation in the vasculature of rats after the onion consumption.

Additionally, as the underlying mechanisms involved in these antiatherosclerotic effects of onion and prevention of CVD are complex and not well known yet, several factors must remain under study and discussion, as for example the synergic implication of sulphur-containing compounds, which can be transformed chemically or enzymatically in the organism with their subsequent formation of $\mathrm{H}_{2} \mathrm{~S}$. Therefore, the implication of sulfides and other sulphur substances, besides other bioactive compounds found in the onion powder are assumed to contribute in the reversion of vascular impairment found in endothelium-dependent vasodilation in the mesenteric vasculature and the enhanced antioxidant status found in the HCO-fed group.

\section{Conclusions}

Since the search for modifications in diet and lifestyle which contribute to the reversion of endothelial dysfunction remains active (e.g. lipid lowering-therapy, n3 fatty acids, vitamin C, folate, etc.) [30,68]; the enrichment of diet with onion ingredients may be discussed as a complementary strategy to prevent or partially modulate vascular dysfunction, reducing some of the risk indexes linked to initial stages of atherosclerosis.

Further investigation is needed to improve the understanding of the mechanisms of action and the implications of onion in the prevention and development of cardiovascular and metabolic diseases, to finally dissect its effects and its possible functions and interactions with other functional compounds.

\section{Competing interests \\ The authors declare that they have no competing interests.}

\section{Authors' contributions}

All authors have significantly contributed to the manuscript. DG-P, CC-C, $B d A$, and CS-M produced the onion powder, contributed to the formulation of the diets, organized and supported the feeding trial, and were involved in the nutritional composition, phytochemical compounds, and antioxidant activity analyses of onion powder, as well as in the plasma cholesterol and triacylglycerides analyses and plasma antioxidant activity analyses. JA, SV, CFS-F, and CP were involved in the endothelium-dependent relaxation analyses in mesenteric microvessels, vascular reactivity analysis, and NADPH oxidase activity. CS-M planned and designed the rat study. All authors contributed in some way in data interpretation, critical discussion of results, and preparation of the manuscript. All authors read and approved the final manuscript.

\section{Acknowledgements}

This work has been financially supported by the Spanish Ministry of Science and Innovation [AGL2010-15910 (subprogram ALI), SAF2011-24648 and SAF2011-28011]. The following projects are also acknowledged: Program Consolider-Ingenio 2010, FUN-C-FOOD, CSD2007-00063 (Spanish Ministry of Science and Innovation), and ALIBIRD, S2009/AGR-1469 (Comunidad de Madrid). CP and CF S-F are engaged in the COST Action BM1005 ENOG.

We acknowledge support of the publication fee by the CSIC Open Access Publication Support Initiative through its Unit of Information Resources for Research (URICI)

\section{Author details}

${ }^{1}$ Institute of Food Science, Technology and Nutrition (ICTAN), Spanish National Research Council (CSIC), José Antonio Novais 10, ES-28040 Madrid, Spain. ${ }^{2}$ Servicio de Histología-Investigación, Instituto Ramón y Cajal de Investigación Sanitaria (IRYCIS), ES-28034 Madrid, Spain. ${ }^{3}$ Departamento de Farmacología, Facultad de Medicina, Universidad Autónoma de Madrid, ES-28029 Madrid, Spain.

Received: 25 October 2014 Accepted: 29 November 2014

Published: 23 December 2014 


\section{References}

1. Stapleton PA, Goodwill AG, James ME, Brock RW, Frisbee JC: Hypercholesterolemia and microvascular dysfunction: interventional strategies. J Inflamm-Lond 2010, 7:54.

2. Madamanchi NR, Runge M: Redox signalling in cardiovascular health and disease. Free Radic Biol Med 2013, 61:473-501.

3. Taverne YJHJ, Bogers Ad JJC, Duncker D, Merkus D: Reactive oxygen species and the cardiovascular system. Oxidative Med Cell Longev 2013, 2013:862423. doi:10.1155/2013/862423.

4. Cuevas AM, Germain AM: Diet and endothelial function. Biol Res 2004, 37:225-230.

5. Andriantsitohaina R, Auger C, Chataigneau T, Étienne-Selloum N, Li H, Martínez MC, Schini-Kerth VB, Laher I: Molecular mechanisms of the cardiovascular protective effects of polyphenols. Br J Nutr 2012, 108:1532-1549.

6. Habauzit V, Morand C: Evidence for a protective effect of polyphenolscontaining foods on cardiovascular health: an update for clinicians. Ther Adv Chronic Dis 2012, 3:87-106.

7. Houston MC: The role of nutrition, nutraceuticals, vitamins, antioxidants, and minerals in the prevention and treatment of hypertension. Altern Ther Health Med 2013, 19:32-49.

8. Wang Y, Chun OK, Song WO: Plasma and dietary antioxidant status as cardiovascular disease risk factors: a review of human studies. Nutrients 2013, 5:2969-3004

9. Garcia-Rios A, Delgado-Lista J, Alcala-Diaz JF, Lopez-Miranda J, Perez-Martinez P: Nutraceuticals and coronary heart disease. Curr Opin Cardiol 2013, 28:475-482.

10. Dal-Ros S, Bronner C, Auger C, Schini-Kerth VB: Red wine polyphenols improve an established aging-related endothelial dysfunction in the mesenteric artery of middle-aged rats: role of oxidative stress. Biochem Biophys Res Commun 2012, 419:381-387.

11. Nogueira L, Knibel M, Torres MR, Nogueira Neto JF, Sanjuliani AF: Consumption of high-polyphenol dark chocolate improves endothelial function in individuals with stage 1 hypertension and excess body weight. Int J Hypertens 2012, 2012:147321. doi:10.1155/2012/147321.

12. Hallund J, Bügel S, Tholstrup T, Ferrari M, Talbot D, Hall WL, Reimann M, Williams CM, Wiinberg N: Soya isoflavone-enriched cereal bars affect markers of endothelial function in postmenopausal women. Br J Nutr 2006, 95:1120-1126.

13. Fuentes F, López-Miranda J, Sánchez E, Sánchez F, Paez J, Paz-Rojas E, Marín C, Gómez P, Jimenez-Perepérez J, Ordovás JM, Pérez-Jiménez F: Mediterranean and low-fat diets improve endothelial function in hypercholesterolemic men. Ann Intern Med 2001, 134:1115-1119.

14. Estruch R, Ros E, Salas-Salvadó J, Covas M-I, Corella D, Arós F, Gómez-Gracia E, Ruiz-Gutiérrez V, Fiol M, Lapetra J, Lamuela-Raventos RM, Serra-Majem L, Pintó X, Basora J, Muñoz MA, Sorlí JV, Martínez JA, Martínez-González MA: Primary prevention of cardiovascular disease with a Mediterranean diet. N Engl J Med 2013, 368:1279-1290.

15. Corzo-Martínez M, Corzo N, Villamiel M: Biological properties of onions and garlic. Trends Food Sci Tech 2007, 18:609-625.

16. Griffiths G, Trueman L, Crowther T, Thomas B, Smith B: Onions - a globa benefit to health. Phytother Res 2002, 16:603-615.

17. Kim J-M, Park E: Effect of onion consumption on cardiovascular disease in human intervention studies: a literature review. J Korean Soc Food Sci Nutr 2010, 39:1565-1572.

18. Vazquez-Prieto MA, Miatello RM: Organosulfur compounds and cardiovascular disease. Mol Asp Med 2010, 31:540-545.

19. Benítez V, Mollá E, Martín-Cabrejas MA, Aguilera Y, López-Andréu FJ, Esteban RM: Onion (Allium cepa L.) by-products as source of dietary fiber: physicochemical properties and effect on serum lipid levels in high-fat fed rats. Eur Food Res Technol 2012, 234:617-625.

20. González-Peña D, Colina-Coca C, Char CD, Cano MP, de Ancos B, SánchezMoreno $C$ : Hyaloruronidase inhibiting activity and radical scavenging potential of flavonols in processed onion. J Agric Food Chem 2013, 61:4862-4872.

21. Reeves PG: Components of the AIN-93 diets as improvements in the AIN-76A diet. J Nutr 1997, 127:838S-841S

22. Roldán-Marín E, Krath BN, Poulsen M, Binderup M-L, Nielsen TH, Hansen M, Barri T, Langkilde S, Cano MP, Sánchez-Moreno C, Dragsted LO: Effects of an onion by-product on bioactivity and safety markers in healthy rats. Br J Nutr 2009, 102:1574-1582

23. Roldán-Marín E, Jensen Rl, Krath BN, Kristensen M, Poulsen M, Cano MP, Sánchez-Moreno C, Dragsted LO: An onion byproduct affects plasma lipids in healthy rats. J Agric Food Chem 2010, 58:5308-5314.
24. Association of Official Analytical Chemists: Official Methods of Analysis of Association of Official Analytical Chemists (AOAC) International. 16th edition. Washington, DC: Association of Official Analytical Chemists; 1995.

25. Colina-Coca C, de Ancos B, Sánchez-Moreno C: Nutritional composition of processed onion: S-alk(en)yl-L-cysteine sulfoxides, organic acids, sugars, minerals and vitamin C. Food Bioprocess Technol 2014, 7:289-298.

26. Colina-Coca C, González-Peña D, Vega E, de Ancos B, Sánchez-Moreno C: Novel approach for the determination of volatile compounds in processed onion by headspace gas chromatography-mass spectrometry (HS GC-MS). Talanta 2013, 103:137-144

27. Rodríguez-Mañas L, Angulo J, Vallejo S, Peiró C, Sánchez-Ferrer A, Cercas E, López-Dóriga P, Sánchez-Ferrer CF: Early and intermediate Amadori glycosylation adducts, oxidative stress, and endothelial dysfunction in the streptozotocin-induced diabetic rats vasculature. Diabetologia 2003, 46:556-566.

28. Vallejo S, Romacho T, Angulo J, Villalobos LA, Cercas E, Leivas A, Bermejo E, Carraro R, Sánchez-Ferrer CF, Peiró C: Visfatin impairs endotheliumdependent relaxation in rat and human mesenteric microvessels through nicotinamide phosphoribosyltransferase activity. PLoS One 2011, 6:e27299.

29. Mulvany MJ, Halpern W: Contractile properties of small arterial resistance arteries in spontaneously hypertensive and normotensive rats. Circ Res 1977, 41:19-26.

30. Widlansky ME, Gokce N, Keaney JF, Vita JA: The clinical implications of endothelial dysfunction. J Am Coll Cardiol 2003, 42:1149-1160.

31. Mauricio MD, Aldasoro M, Ortega J, Vila JM: Endothelial dysfunction in morbid obesity. Curr Pharm Des 2013, 19:5718-5729.

32. Rupérez Al, Gil A, Aguilera CM: Genetics of oxidative stress in obesity. Int J Mol Sci 2014, 15:3118-3144.

33. Tabas I, Williams KJ, Boren J: Subendothelial lipoprotein retention as the initiating process in atherosclerosis: update and therapeutic implications. Circulation 2007, 116:1832-1844.

34. Libby $P$, Ridker PM, Hansson GK: Progress and challenges in translating the biology of atherosclerosis. Nature 2011, 473:317-325.

35. Kim MJ, Jung HN, Kim KN, Kwak HK: Effects of cranberry powder on serum lipid profiles and biomarkers of oxidative stress in rats fed an atherogenic diet. Nutr Res Pract 2008, 2:158-164.

36. Bocanegra A, Bastida S, Bened J, Nus M, Sánchez-Montero JM, Sánchez-Muniz FJ: Effect of seaweed and cholesterol-enriched diets on postprandial lipoproteinaemia in rats. Br J Nutr 2009, 102:1728-1739.

37. Olivero-David R, Schultz-Moreira A, Vázquez-Velasco M, González-Torres L, Bastida S, Benedí J, Sanchez-Reus MI, González-Muñoz MJ, Sánchez-Muniz FJ: Effects of Nori- and Wakame-enriched meats with or without supplementary cholesterol on arylesterase activity, lipaemia and lipoproteinaemia in growing Wistar rats. Br J Nutr 2011, 106:1476-1486.

38. Chijimatsu T, Okuda Y, Yamada K, Oda H, Mochizuki S: The fat and protein fractions of freshwater clam (Corbicula fluminea) extract reduce serum cholesterol and enhance bile acid biosynthesis and sterol excretion in hypercholesterolaemic rats fed a high-cholesterol diet. Br J Nutr 2011 105:526-534.

39. Khaled HB, Ghlissi Z, Chtourou Y: Effect of protein hydrolysates from sardinelle (Sardinella aurita) on the oxidative status and blood lipid profile of cholesterol-fed rats. Food Res Int 2012, 45:60-68.

40. Abbas AM, Sakr HF: Simvastatin and vitamin E effects on cardiac and hepatic oxidative stress in rats fed on high fat diet. J Physiol Biochem 2013, 69:737-750

41. Belguith-Hadriche $O$, Bouaziz M, Jamoussi K, Simmonds MS, El Feki A Makni-Ayedi F: Comparative study on hypocholesterolemic and antioxidant activities of various extracts of fenugreek seeds. Food Chem 2013, 138:1448-1453.

42. Souza e Silva L, Mayrink de Miranda A, Lopes de Brito C, Dos Santos RC, Pedrosa ML, Silva ME: Diet supplementation with beta-carotene improves the serum lipid profile in rats fed a cholesterol-enriched diet. J Physiol Biochem 2013, 69:811-820.

43. Adaramoye OA, Akanni OO: Effects of methanol extract of breadfruit (Artocarpus altilis) on atherogenic indices and redox status of cellular system of hypercholesterolemic male rats. Adv Pharmacol Sci 2014 2014:605425. doi:10.1155/2014/605425.

44. Van der Veen JN, Havinga R, Bloks WW, Groen AK, Kuipers F: Cholesterol feeding strongly reduces hepatic VLDL-triglyceride production in mice lacking the liver X receptor a. J Lipid Res 2007, 48:337-347. 
45. Werner A, Havinga R, Bos T, Bloks WW, Kuipers F, Verkade HJ: Essential fatty acid deficiency in mice is associated with hepatic steatosis and secretion of large VLDL particles. Am J Physiol Gastrointest Liver Physiol 2005, 288:G1150-G1158.

46. Gabler NK, Ostrowska E, Sterling SJ, Jones RB, Tatham BG, Eagling DR, Jois $M$, Dunshea FR: Consumption of raw brown onions variably modulate plasma lipid profile and lipoprotein oxidation in pigs fed a high-fat diet. J Sci Food Agric 2005, 85:154-160.

47. Gabler NK, Osrowska E, Imsic M, Eagling DR, Jois M, Tatham BG, Dunshea FR: Dietary onion intake as part of a typical high fat diet improves indices of cardiovascular health using the mixed sex pig model. Plant Foods Hum Nutr 2006, 61:179-185.

48. Lassègue B, Griendling KK: NADPH oxidases: functions and pathologies in the vasculature. Arterioscler Thromb Vasc Biol 2010, 30:653-661.

49. Lee $\mathrm{B}$, Jung J-H, Kim H-S: Assessment of red onion on antioxidant activity in rat. Food Chem Toxicol 2012, 50:3912-3919.

50. Hyun S-W, Jang M, Park SW, Kim EJ, Jung Y-S: Onion (Allium cepa) extract attenuates brain edema. Nutrition 2013, 29:244-249.

51. Papageorgiou N, Tousoulis D, Katsargyris A, Charakida M, Androulakis E, Siasos G, Tentolouris C, Stefanadis C: Antioxidant treatment and endothelial dysfunction: Is it time for flavonoids? Recent Patents Cardiovasc Drug Discov 2013, 8:81-92.

52. Sanchez M, Lodi F, Vera R, Villar IC, Cogolludo A, Jimenez R, Moreno L, Romero M, Tamargo J, Perez-Vizcaino F, Duarte J: Quercetin and isorhamnetin prevent endothelial dysfunction, superoxide production, and overexpression of p47phox induced by angiotensin II in rat aorta. J Nutr 2007, 137:910-915.

53. Shen Y, Ward N, Hodgson J, Puddey IB, Wang Y, Zhang D, Maghzal GJ, Stocker R, Croft KD: Dietary quercetin attenuates oxidant-induced endothelial dysfunction and atherosclerosis in apolipoprotein $\mathrm{E}$ knockout mice fed a high-fat diet: a critical role for hemeoxygenase-1. Free Radic Biol Med 2013, 65:908-915.

54. Indra MR, Karyono S, Ratnawati R, Malik SG: Quercetin suppresses inflammation by reducing ERK1/2 phosphorylation and NF kappa B activation in leptin-induced human umbilical vein endothelial cells (HUVECs). BMC Res Notes 2013, 6:275.

55. Bischoff SC: Quercetin: potentials in the prevention and therapy of disease. Curr Opin Clin Nutr Metab Care 2008, 11:733-740.

56. Nair MP, Mahajan S, Reynolds JL, Aalinkeel R, Nair H, Schwartz SA, Kandaswami C: The flavonoid quercetin inhibits proinflammatory cytokine (TNFa) gene expression in normal peripheral blood mononuclear cells in via modulation of the NF-к $\beta$ system. Clin Vaccine Immunol 2006, 13:319-328.

57. Phang M, Lazarus S, Wood LG, Garg M: Diet and thrombosis risk: nutrients for prevention of thrombotic disease. Semin Thromb Hemost 2011, 37:199-208.

58. Alpsoy S, Uygur R, Aktas C: The effects of onion (Allium cepa) extract on doxorubicin-induced apoptosis in aortic endothelial cells. J Appl Toxicol 2013, 33:364-369.

59. Gorinstein S, Leontowicz H, Leontowicz M, Jastrzebski Z, Najman K, Tashma Z, Katrich E, Heo BG, Cho JY, Park YJ, Trakhtenberg S: The influence of raw and processed garlic and onions on plasma classical and non-classical atherosclerosis indices: investigations in vitro and in vivo. Phytother Res 2010, 24:706-714.

60. Li W, Tang C, Jin H, Du J: Effects of onion extract on endogenous vascular $\mathrm{H} 2 \mathrm{~S}$ and adrenomedulin in rat atherosclerosis. Curr Pharm Biotechnol 2011, 12:1427-1439.

61. Cacanyiova S: Nitric oxide and hydrogen sulfide - contribution of gaseous messengers to the cardiovascular control. Curr Pharm Biotechnol 2011, 12:1292.

62. McNeill JR, Jurgens TM: A systematic review of mechanisms by which natural products of plant origin evoke vasodilatation. Can J Physiol Pharmacol 2006, 84:803-821.

63. Heumüller S, Wind S, Barbosa-Sicard E, Schmidt HHHW, Busse R, Schröder K, Brandes RP: Apocynin is not an inhibitor of vascular NADPH oxidases but an antioxidant. Hypertension 2008, 51:211-217.

64. Touyz RM: Apocynin, NADPH oxidase and vascular cells: a complex matter. Hypertension 2008, 51:172-174.

65. Cerwinka WH, Granger DN: Influence of hypercholesterolemia and hypertension on ischemia-reperfusion induced P-selectin expression. Atherosclerosis 2001, 154:337-344
66. Ronald JA, Chen JW, Chen Y, Hamilton AM, Rodríguez E, Reynolds F, Hegele RA, Rogers KA, Querol M, Bogdanov A, Weissleder R, Rutt BK: Enzymesensitive magnetic resonance imaging targeting myeloperoxidase identifies active inflammation in experimental rabbit atherosclerotic plaques. Circulation 2009, 120:592-599.

67. Durand MJ, Gutterman DD: Diversity in mechanisms of endothelium-dependent vasodilation in health and disease. Microcirculation 2013, 20:239-247.

68. Liu L, Yan L, Chen YH: A role for diallyl trisulfide in mitochondrial antioxidative stress contributes to its protective effects against vascular endothelial impairment. Eur J Pharmacol 2014, 725:23-31.

doi:10.1186/1743-7075-11-57

Cite this article as: González-Peña et al:: High-cholesterol diet enriched with onion affects endothelium-dependent relaxation and NADPH oxidase activity in mesenteric microvessels from Wistar rats. Nutrition \& Metabolism 2014 11:57.

\section{Submit your next manuscript to BioMed Central and take full advantage of:}

- Convenient online submission

- Thorough peer review

- No space constraints or color figure charges

- Immediate publication on acceptance

- Inclusion in PubMed, CAS, Scopus and Google Scholar

- Research which is freely available for redistribution 